\title{
Examining the Evidence that Testing Benefits Subsequent Information Retrieval
}

\author{
THINLEY WANGDI \\ School of Languages and General Education, \\ Walailak University, Thailand \\ thinley11@gmail.com
}

\begin{abstract}
This study examines the effect of frequent testing on students' ability to retain the vocabulary and grammar materials learned in the classroom. A quasi-experimental research was employed, involving a sample of 50 Thai vocational students that was purposively recruited for this study. They were divided into two groups, each comprising 25 students. The experimental group received a test and corrective feedback after each unit of the course while the control group did not receive any unit test. The retention test scores were then compared to gauge the performance of the experimental and control groups. In doing this, the experimental group significantly outscored the control group in the retention test. The study found that frequent testing of the students in the course of their study had helped them retain vocabulary and grammar knowledge. The frequent testing may, therefore, be considered as one of the teaching methods to help students to have better retention of vocabulary and grammar knowledge.
\end{abstract}

Keywords: frequent testing; corrective feedback; vocabulary; grammar; retention

\section{INTRODUCTION}

\section{RATIONALE OF THE STUDY}

Frequent testing is part of formative assessment that is integrated into a course to acknowledge the learning progress (McDaniel et al., 2012). Frequent tests are fundamentally carried out to help improve classroom materials and learners' retention of what is taught (Leung \& Kier, 2017; Karpicke \& Roediger, 2007). However, the frequency in which tests are administered seemingly differ from one institution to institution. This could be due to existing disparities in belief among the researchers, educators and teachers. Some believe that more tests help learners yield better academic performance (Wiliam, 2011), while others believe that a test alone has a small role in the learners' academic performance (Haberyan, 2003).

Leung and Kier (2017) claimed that frequently testing learners in a course encourages them to learn more and increase their learning regularity, which enables learners to improve their long-term retention ability, with increased retention accuracy of the learned materials (Wooldridge, 2014). The positive impact of frequent testing was further acknowledged by Larsen and Butler (2009), who reported that repeated testing help learners retain the classroom materials because testing involves considerably greater effort to retrieve what has been learnt. In addition, Trumbo et al. (2016) highlighted that frequent testing enhances learners' academic performance by helping them get familiarised with conceptually related content through repeated exposures to the classroom materials.

Furthermore, a number of studies have pointed out that learners also acknowledge the positive effects of frequent testing on their learning. For example, Siddiqui et al. (2017) posited that $84 \%$ of their participants agreed on the positive effects of frequent testing in their learning. Participants who received frequent testing found it beneficial to the improvement in their learning experience. Similarly, Thirey (2011) and Vaessen et al. (2017) reported that the majority of the participants in their studies responded positively to the effect of frequent testing on their final academic performance. 
In contrast to what has been pointed out on the positive effects of frequent testing in the classroom, some researchers (e.g. Karpicke \& Roediger, 2007) rejected the assumption that frequent testing helps in improved retention ability and final academic performance. For them, frequent testing is a cause of poor-quality education. They claim that frequent testing directs students' efforts more towards the test performance or test scores in lieu of learning. Besides that, Mines (2014) commented that frequent testing is a waste of time; if the test does not have any positive effects on learners' learning performance, valuable instructional time is wasted.

The use of frequent testing in the classroom was further discouraged by the metaanalysis of Başol and Johanson (2009), who stated that frequent conducting of tests showed no significant improvement in the learning performance of the learners. A similar meta-analysis study by Bangert-Drowns et al., (1991) on the effect of frequent classroom testing on learners' final performance showed that out of 35 studies taken for the analysis, 29 studies claimed that frequent testing has a relatively positive effect on learning outcome, and the other 6 studies demonstrated a negative or neutral effect.

In view of its confounding nature and inconclusive claims made by researchers on the effects of frequent testing on retention ability and academic performance. The current study was carried out. It aimed at finding the effect of frequent testing on the retention ability of the classroom materials (vocabulary and grammar) and the final learning performance (i.e. vocabulary, grammar, reading comprehension, writing). Further, to bring a stronger conclusion on the effects of frequent testing, this study also aimed at demonstrating the effect of frequent testing on participants with different English language abilities.

\section{WHY VOCABULARY AND GRAMMAR?}

Research investigating the impact of frequent testing on learner's retention ability has been carried out by using various aspects of language as a tool (e.g. Wooldridge, 2014; Butler \& Roediger, 2007; Roediger \& Karpicke, 2006). Some of these include the effect of frequent classroom testing on retention of reading materials, classroom lecture, vocabulary, grammar and so on. As for the current study, the learners' retention ability is determined by the two aspects of the language, vocabulary and grammar knowledge.

Vocabulary knowledge was mostly measured because it is believed to be one of the most essential components of language, particularly in second language acquisition (Lee et al., 2019; Choo et al., 2017). Indeed, it is commonly stated as the heart of language acquisition (Coady and Huckin, 1997) as it defines the learners' mastery in the target language. Good lexical knowledge of any language enables learners to master the target language and help improve their communicative skills ( Lee et al., 2019). Alqahtani (2015) reported that learners can acquire the target language only through acquiring their corresponding vocabulary, and the researcher also suggested that both teachers and learners must know the essence of vocabulary for the successful acquisition of the target language.

Similarly, the syntactic or grammar knowledge of the language has been given equal importance as it helps ease foreign language acquisition (Sun, 2017). By acquiring good syntactic knowledge of the target language, learners are likely to increase their language comprehension skills with better outcomes. Therefore, the knowledge of grammar carries equal weight as that of vocabulary for better and accurate language learning outcomes (Debata, 2013). In addition, Loewen et al. (2009) pointed out that there is a huge correlation between the vocabulary and grammar knowledge of the language and language learning achievement, particularly, in the field of second language acquisition. 


\section{FREQUENT TESTING AND RETENTION OF CLASSROOM MATERIALS}

Frequent testing has been defined and interpreted in numerous ways based on the frequency of the test (Gholami \& Moghaddam, 2013). For instance, according to Kling et al. (2005), frequent testing is a formative test which is administered on a monthly basis while earlier researchers have defined it as routine tests done weekly (Keys, 1934) and daily (Dineen, 1989) to assess learning progress. Irrespective of its frequency, frequent testing can be defined as a classroom task in which each individual learner must be interested in it as it helps them motivate to learn more than their actual practices (Öncül, 2017, p. 7). In fact, frequent testing was found to be one of the primary strategic choices used by educators to improve learning ability and learning consistency. The most common forms of frequent tests used in the field of teaching and learning are short quizzes (McDaniel et el., 2012).

Moreover, it has been identified that longer retention of classroom materials is one of the major contributions of frequent testing as it gives learners an additional exposure to the materials (Butler \& Roediger, 2007). Prior research has evidenced the impact of frequent testing on learners' retention in different subjects and different domains of human psychology. For example, Roediger and Karpicke (2006) investigated the relationship between frequent testing and long-term retention of language reading with 120 undergraduate students aged 18 -24 years. The retention test was done on the reading courses designed specifically for the study. The finding showed that repeated testing on reading materials relatively improved the participants' ability to remember the materials. This shows that retention ability can be improved with increased frequency of class tests which eventually helps learners to have better final academic performance.

Furthermore, Butler and Roediger (2007) reported that frequent conducting of tests helped students retain the lecture materials taught in the classroom. The sample of the study was 27 undergraduate students. The study was carried out in a simulated classroom setting. To examine the participants' ability to retain the classroom lecture materials. They were given tests frequently on lecture materials through multiple choice questions and short answer questions. After checking students' answers to the tests, they were given feedback on the answers by the instructor in both multiple-choice questions and short answer questions. The result revealed that frequent testing on the classroom lecture materials improved the students' retention of the learnt materials. Perhaps the repeated quiz tests (frequent testing) after the lecture may have given students additional time to revisit the materials, which improved their retention ability.

Carpenter et al. (2009) also investigated the relationship between frequent testing and the retention ability of students. A total of $758^{\text {th }}$ grade students participated in the study, and were assessed on U.S history facts. The facts were reviewed in two ways: by restudying and through testing. The retention test was administered sixteen-weeks after the day of the treatment. The result revealed that students could significantly remember U.S. history facts which were reviewed through frequent testing compared to the restudied materials. The researchers claimed that frequent tests significantly improved the retention ability of students.

Recently, a meta-analysis by Adesope and Trevisan (2017) on the benefits of testing in learning and long-term retention confirmed that repeated testing of learning materials is beneficial in recalling learned information and significantly improves long-term retention. They reviewed 118 experimental studies that examined the difference in final performance between the participants under the practice of testing and non-testing. The findings from their meta-analysis concluded that testing helps to enhance learners' ability to learn and retain the classroom materials, irrespective of its classroom settings (classroom-based or laboratorybased). They have however stressed the variation of impact on the different levels of students; 
they came up with the conclusion that testing is robust and helps to enhance learning in all educational levels, albeit having slight differences in effect.

Besides the convergent conclusions from various studies and their findings on the positive effects of frequent testing in learning and retention ability, a study conducted by Wooldridge et al. (2014) found that frequent testing was not applicable and did not help in enhancing learners' retention ability unless the test items are repeated. They claimed that the students could retain more only if the items of retention tests and classroom formative tests are identical, making it clear for further research needed in this area.

\section{FREQUENT TESTING WITH FEEDBACK}

Despite being vital, feedback often takes the back seat in the educational process (Nusrat et al., 2019). However, literature on frequent testing revealed that, coupled with feedback, it can be beneficial in the process of assessment. Therefore, feedback, particularly corrective feedback is critical while giving frequent tests to the learners. Feedback can be provided to the learners by simply making them aware of their test performance, or by giving remediation or correct answers on their test items (Phelps, 2012). Typically, without feedback assessment may do little good since students may not be aware of where to make improvements. Through feedback teachers are able to customize the learning materials according to the needs of students indicated in the tests score. Further, it is possible that consistent feedback can attest the learned materials providing a foundation for further learning. In fact, prior research has clearly highlighted that testing with feedback benefits subsequent and later retrieval of tested information (Thomas \& McDaniel, 2013).

Additionally, Öncül $(2017$, p. 8 ) has also reaffirmed it with the evidence from his findings where both teachers and learners have responded positively on the significance of feedback in frequent tests. In his discussion, it was pointed out that when feedback is immediate and constructive the outcomes of frequent testing tend to be better. It was also suggested that tests simply become an indicative score if not accompanied with feedback, especially for the lower performing students. Therefore, subsequent corrective feedback could be beneficial when provided after each test.

\section{CONCEPTUAL FRAMEWORK OF THE STUDY}

This paper investigates the effects of frequent testing with feedback on subsequent retrieval of the classroom materials. A quantitative research method was used in this study. Researcher used a quasi-experimental method in which the independent variable is frequent tests, while dependent variable is the obtained vocabulary and grammar scores from the tests (mid-term, final and retention). The intervention stage in the conceptual framework includes corrective feedback such as giving them the right answers and remediation on the test items. The details in which the experiment was carried out is given in the data collection section. The conceptual framework is presented below.

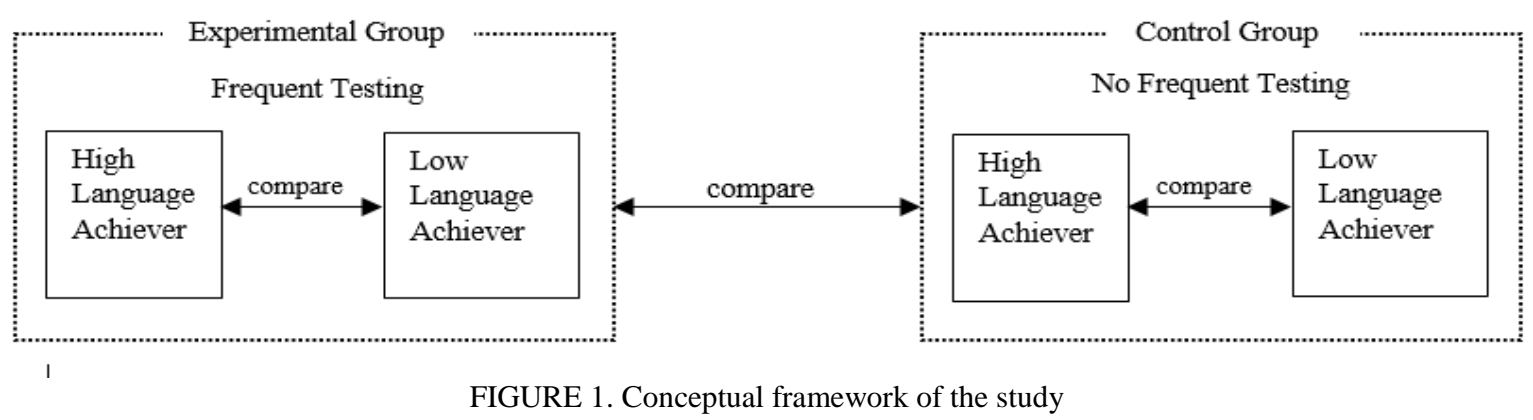




\section{RESEARCH OBJECTIVES AND QUESTIONS}

The research objectives included the following:

1) To investigate the effectiveness of frequent testing with corrective feedback on learner's material retention ability

2) To investigate the degree to which frequent testing can be beneficial to the language learners

Base on the said objectives, two research questions were presented:

1) Do frequent testing help learners retain vocabulary and grammar knowledge learned in the classroom materials?

2) To what extent the frequent testing is beneficial to the language learners?

\section{METHODOLOGY}

\section{PARTICIPANTS}

A total of 50 second-year students from two different sections of the certificate course in Songkhla Vocational College, Thailand were purposively recruited as participants for this study. They were divided into two groups: the experimental group and the control group, each comprising 25 students. The study included 42 female and 8 male participants whose ages range from fifteen to seventeen. All the participants were taking a general English course with a textbook entitled "English for Life" (Hutchinson, 2003), consisting of 10 units. As reflected by their previous year's English grades the experimental group $(\bar{x}=2.54, S . D=0.71)$ and the control group $(\overline{\mathrm{x}}=2.56, \mathrm{~S} . \mathrm{D}=0.70)$ had a similar baseline language proficiency grade.

Simple comparison of two groups was not enough. Further investigation on retention ability of participants with different language abilities was needed to solidify the findings. Therefore, the experimental and control group were subdivided into high and low language achievers based on their previous English language GPA (high achievers: GPA $>=3$ and low: GPA $<=2$ out of 4). Rest of the students whose GPA were in between 2.1 and 2.9 were excluded as it wasn't the focus group of the present study.

\section{RESEARCH INSTRUMENTS}

UNIT TEST

After every unit of the course textbook, a unit test was conducted. Each unit test consisted of 25 items, of which 15 were vocabulary and 10 were grammar items. All the items were tested in the form of gap-filling and matching. The unit tests were developed and administered by the researcher. The first five units were examined before the institute's midterm examination and whereas the other five units prior to the institute's final term examination.

\section{MIDTERM AND FINAL TEST}

The course's midterm and final examinations were set and conducted by the institution. The scores of these two examinations represented the learning achievement of the students. The midterm test included materials taught from units 1 to 5 and the final test included units 6 to 10. Both the midterm and final tests consisted of 40 items, of which 20 were vocabulary, 10 focused on grammar and another 10 on reading comprehension and writing. In this study, however, only the scores of vocabulary and grammar were considered and analysed. 


\section{RETENTION TEST}

A total of 50 items for the retention test were randomly selected from the vocabulary and grammar sections of both the midterm and final tests, 25 items from each test. The retention test consisted of 30 vocabulary and 20 grammar items.

\section{DATA COLLECTION}

The data were collected according to the following steps.

1) Five units (units 1-5) were taught to both the experimental and control groups by the same class teacher. Both groups received 2 hours' instructional time per week in different class settings. The experimental group was given a 20-minute unit test after the completion of each unit of the course. The experimental group was informed of their test scores in the following week and subsequently, corrective feedback was given on the test items. On the other hand, the control group did not receive any unit tests except for the routine forms of feedback on their grammar and vocabulary development through assignments and homework. This routine feedback was common for both groups.

2) After the completion of unit 5, the midterm test was administered to both the experimental and control groups as scheduled by the institution.

3) Both groups received another 5 lessons (units $6-10$ ) after the midterm test. Similarly, the experimental group took a 20-minute unit test after each unit (6-10) of the course besides the routine assignments and homework while the control group carried only its assignments and homework. After the completion of the last unit, the final test was administered to both groups.

4) Two weeks after the final test, both groups took the retention test which consisted of 30 items on vocabulary and 20 on grammar. These items were randomly but equally selected from both the midterm and final tests.

DATA ANALYSIS

Data obtained from all three tests (midterm, final and retention) were analysed. They were later interpreted to answer each research question. Data obtained was analysed using the Statistical Package for the Social Sciences (SPSS) program, version 24. Mean, standard deviation and tvalue of the independent sample t-tests were used to describe the participants' performance in the final learning achievement tests (midterm and final) and retention test.

\section{RESULTS}

RQ1: Do frequent testing help learners retain the vocabulary and grammar knowledge learned in the classroom materials?

To answer this question, the retention test scores of the experimental and the control group were compared by using a descriptive analysis such as mean, standard deviation and tvalue of the independent sample t-test. The analysis is presented in Table 1. Before proceeding to carry out the t-test, the assumption of normality was tested. By doing this, it was found that the sample data for both experimental and control group are little skewed and kurtotic but with minimal deviation from the normality. The data of present study was thus assumed normally distributed in terms of skewness (experimental group $=1.76 \&$ control group $=1.47$ ) and kurtosis (experimental group $=0.74 \&$ control group $=-0.53$ ) since $\mathrm{z}$-value was in between 1.96 and +1.96 . 
TABLE 1. Comparisons of the learning achievement (midterm + final Scores) test and the retention scores between the experimental and control groups

\begin{tabular}{lcccccc}
\hline \multirow{2}{*}{ Groups $(\mathrm{N})$} & \multicolumn{2}{c}{ Learning achievement } & \multicolumn{2}{c}{ Retention score } & t-value & 2-taled \\
& \multicolumn{2}{c}{ Total score $=50$} & \multicolumn{2}{c}{ Total score $=50$} & & sig. \\
& Mean $(\overline{\mathrm{x}})$ & SD & Mean $(\overline{\mathrm{x}})$ & SD & & .796 \\
\hline Experimental $(25)$ & 30.56 & 8.60 & 30.04 & 9.32 & .260 & $.001 *$ \\
Control $(25)$ & 25.30 & 7.44 & 19.84 & 6.05 & 3.77 & .05 \\
\hline
\end{tabular}

*significant at $\mathrm{p}<.05$

Firstly, the analysis showed that frequent testing did help participants in the experimental group to have better learning achievement performance. As illustrated in table 1. the combined mean scores of the midterm and final tests for the experimental group were 30.56, whereas the control group was 25.30. Similarly, in the retention test, the experimental group secured mean scores of 30.04 while the control group secured only 19.84. The means scores difference for both the learning achievement tests and the retention test between the two groups was statistically significant at $\mathrm{p}<0.05$. The participants in the experimental group outscored in the final learning achievement tests as well as in the retention test.

On the other hand, the participants' retention ability was examined by comparing their learning achievement scores and the retention test scores. In so doing, it was found that the average means of the learning achievement scores (30.56) and the retention score (30.04) of the participants in the experimental group were consistent, even after three weeks gap with no statistically significant difference. They could retain almost all the classroom materials that they had to retain for the midterm and final tests. On the contrary, a significant decline in the retention test score (19.84) was observed for the participants in the control group when it was compared with their learning achievement tests scores (25.30), three weeks before. They scored relatively low in their retention test, indicating their failure to retain the classroom materials that they had learned in the classroom for both the midterm and final tests.

\section{RETENTION PERFORMANCE OF PARTICIPANTS WITH DIFFERENT LANGUAGE ABILITY.}

RQ2: To what extent the frequent testing is beneficial to the language learners?

To gain deeper insight into the effect of frequent testing and its influence on learners' retention ability, a detailed comparison of the retention scores were made between the high and low language achievers in both groups. This was done in order to examine retention ability of the high and low language achievers from the two different groups (experimental and control group) in terms of what they had learned for the midterm and the final tests respectively. It should be noted that both groups (experimental and control) received the retention test 3 months after the midterm test and 2 weeks after the final test. The analysis is presented in Tables $2 \mathrm{a}$ and $2 \mathrm{~b}$.

TABLE 2a. High and low language achievers' retention scores of two different retention time intervals for the experimental group (total score $=25$ for midterm/final/retention)

\begin{tabular}{lccccccccc}
\hline & & Midterm & Retention & t-value & 2- tailed sig. & Final & Retention & $\begin{array}{c}\mathrm{t}- \\
\text { value }\end{array}$ & $\begin{array}{c}\text { 2- tailed } \\
\text { sig. }\end{array}$ \\
& & $(\overline{\mathrm{x}})$ & $(\overline{\mathrm{x}})$ & & & & $(\overline{\mathrm{x}})$ & $(\overline{\mathrm{x}})$ & \\
\hline Experi- & High & 18.37 & 18 & .275 & .791 & 19.87 & 18.38 & 1.323 & .277 \\
mental & Low & 12.12 & 12.05 & -.258 & .803 & 14.25 & 13.75 & .342 & .743 \\
\hline
\end{tabular}

The findings in this section are all based on the comparison of the participants' midterm scores and their retention scores. This was done in order to establish a realistic retention time interval of 3 months for the participants to retain the classroom materials. In doing so, surprisingly, there was no significant difference between the midterm mean scores and their 
retention mean scores for both high and low language achievers of the experimental group, The participants of the high achiever group scored 18.37 out of 25 in the midterm test and 18 out of 25 in the retention test, a non-significant decrease of .37 (18.37-18). This was the same case with the low language achiever group participants, they scored 12.12 in the midterm test and 12.05 in the retention test, again a non-significant decline, albeit markedly lower in score compared to the participants of the high language achiever group, and it comes as no surprise to us.

Furthermore, to solidify the findings on the benefits of frequent testing on the leaner's retention ability, an attempt was made to examine the effect of frequent testing on the participants' retention ability with two different retention time intervals (3 months and 2 weeks). Interestingly, there was no significant decrease nor increase in the participants' retention scores for the two different retention time intervals. It was notably the same on average in both cases, for 3 months and 2 weeks intervals of the retention time. The participants could retain almost the same amount of the classroom materials that they had learned before and after the midterm or before the final test, irrespective of the retention time interval (see Table 2a). In other words, for experimental group, retention ability of students was not affected by the time elapsed from materials taught to materials tested for its retention.

TABLE 2b. High and low language achievers' retention scores for the control group (total score $=25$ for midterm/final/retention)

\begin{tabular}{cccccc} 
& & Midterm & Retention & t-value & 2- tailed sig. \\
& & $(\overline{\mathrm{x}})$ & $(\overline{\mathrm{x}})$ & & \\
\cline { 2 - 7 } Control & High & 15.12 & 10.75 & 2.895 & $.023 * *$ \\
& Low & 11.25 & 6.37 & 4.754 & $.002 *$ \\
\hline
\end{tabular}

*significant at 0.01 level ** significant at 0.05 level

As for the control group as shown in Table $2 b$, retention test scores were significantly low when compared with midterm scores. Whether high or low language achiever subset did not make any difference in their retention ability. The average mean scores of the high language achiever participants in the midterm and the retention tests were 15.12 and 10.75 , respectively, a difference of 4.37 (15.12-10.75). Similarly, the average mean scores of the low language achiever participants in the midterm and the retention tests were 11.25 and 6.37 , with almost the same difference as that of the high language achiever.

\section{DISCUSSION AND CONCLUSION}

Although the present findings were solely based on the comparison of the obtained scores of the two components of the English language (vocabulary and grammar), it is worth noting that frequently testing in the classroom can help improve learners' overall academic performance. The data illustrated in Table 1 clearly shows that the group that received frequent tests performed better than the group that did not receive any test. The finding also agrees with most of the previous studies highlighting the positive effect of frequent testing (e.g. Butler and Roediger, 2007; Roediger and Karpicke, 2006). Moreover, a couple of recent research studies have acknowledged the assumption made on the benefits of frequent testing in improving learners learning process and academic performance (Leung \& Kier, 2017; Nejati, 2016; Schugel, 2016).

The present findings also revealed the experimental group that received frequent tests having significantly better retention scores than the control group. The finding was in line with some previous studies where improvement in retention ability through frequent testing was underscored (e.g. Roediger et al., 2011; Larsen \& Butler, 2009). It seems that the additional 
exposures to the classroom materials induced by the repeated tests and feedback helped learners to retain the learned materials (McDaniel \& Masson, 1985 cited in Butler \& Roediger, 2007). Secondly, the efforts that the experimental group has put in for the classroom tests may have familiarised them with the classroom materials better, resulting in better retention scores (Trumbo et al., 2016). In addition to this, corrective feedback given by the instructor to the learners in the form of remediation on the test items after each unit test in the following week may led into better understanding and retention of the materials (Doughty \& Long, 2003). Although it is said that the impact of corrective feedback may vary in ways the learners react to, for individual learner (Sheen, 2004), surprisingly, the current findings found no disparities among the learners learning outcome after giving frequent tests and corrective feedback; frequent testing and corrective feedback seemed beneficial to all levels of learners (Adesope \& Trevisan, 2017). The finding is illustrated in Table 2a, where a non-significant difference in the classroom materials retained by the learners with high and low language achievers was revealed for those who received frequent testing with corrective feedback.

In addition, the data presented in Table 2 a gave us two meaningful lessons. Firstly, an evidence that frequent testing with corrective feedback as a helpful practice to help learners improve their long-term retention ability (Roediger \& Karpicke, 2006). In the current finding, both high and low language achievers of the experimental group who received frequent tests with corrective feedback could retain the classroom materials that they have learned 3 months prior to the retention test, irrespective of their language abilities. More importantly, this gave us some point to argue over the realistic retention time intervals ( 3 months for this study) over which the learners could possibly remember the learned classroom materials. But on the flip side, both high and low language achievers of the control group have failed to retain substantial amount of the materials that they have learned before the retention test, 3 months to be precise. It seems that routine classroom instructions, assignments and homework that they received from the instructors in the classroom did not help them much in retaining the learned materials. Another interesting finding from the current study was participants' non-significance difference of retention scores for two different intervals of the retention time: 3 months and 2 weeks. Surprisingly, the result revealed less or no effect of retention time intervals to the learner's retention. This further helped solidify and provide a deeper understanding of the positive impact of frequent testing with corrective feedback on learner's retention ability, indicating that frequent testing could be helpful for both short and long-term materials' retention.

\section{IMPLICATIONS}

The present study has provided evidence regarding the benefits frequent testing with corrective feedback has on the academic achievement performance and retention ability of language learners. This finding has useful pedagogical implications in the SLA (Second language acquisition) field for all levels of learners. Thus, pedagogically, the incorporation of frequent testing with corrective feedback in ESL and EFL schools and institutions may be recommended. As demonstrated by this study, frequent testing followed by corrective feedback system may particularly be useful and beneficial for learners to help them in mastering the vocabulary and grammar. Loewen et al. (2009) asserted that there is a huge correlation between the vocabulary and grammar knowledge with the learner's language acquisition. By keeping this in mind, second language instructors are thus suggested to incorporate frequent testing with corrective feedback in the course to help learners enhance the pace of the language acquisition. More so, literature has defined vocabulary as the heart of language (Coady \& Huckin, 1997) and grammar as a vehicle to a successful language acquisition (Debata, 2013), 
therefore, incorporating frequent testing may prove to be the strongest method of language acquisition.

However, to confirm the findings of the present study, further research is needed on the other aspects of the English language besides vocabulary and grammar, and research in different class settings before a conclusion can be drawn on the effect of frequent classroom testing. Moreover, research on subjects other than the English language may help us gain more valuable insight into the relationship that frequent testing has with the learners' retention ability and their final learning performance.

\section{ACKNOWLEDGEMENT}

I would like to acknowledge Dr. Sandeep Lloyd Kachchhap, Schools of Languages and General Education, Walailak University and Dr. Tashi Wangchuk for their continuous guidance, support and help in developing this present manuscript, especially for their constructive comments and suggestions after having the manuscript proofread.

\section{REFERENCES}

Adesope, O. O., Trevisan, D. A., \& Sundararajan, N. (2017). Rethinking the use of tests: A meta-analysis of practice testing (vol 87, pg 659, 2017). Review of Educational Research, 87(3), 1-1.

Alqahtani, M. (2015). The importance of vocabulary in language learning and how to be taught. International journal of teaching and education, 3(3), 21-34.

Bangert-Drowns, R. L., Kulik, J. A., \& Kulik, C. L. C. (1991). Effects of frequent classroom testing. The Journal of Educational Research, 85(2), 89-99.

Başol, G., \& Johanson, G. (2009). Effectiveness of frequent testing over achievement: A meta-analysis study. Journal of Human Sciences, 6(2), 99-121.

Butler, A. C., \& Roediger III, H. L. (2007). Testing improves long-term retention in a simulated classroom setting. European Journal of Cognitive Psychology, 19(4-5), 514-527.

Carpenter, S. K., Pashler, H., \& Cepeda, N. J. (2009). Using tests to enhance 8th grade students' retention of US history facts. Applied Cognitive Psychology: The Official Journal of the Society for Applied Research in Memory and Cognition, 23(6), 760-771.

Coady, J., \& Huckin, T. (1997). Second language vocabulary acquisition: A rationale for pedagogy. Cambridge University Press.

Choo, L. B., Lin, D. T. A., Singh, M. K. M., \& Ganapathy, M. (2017). The significance of the academic word list among ESL tertiary students in a Malaysian public university. 3L: Language, Linguistics, Literature $\AA, 23(4)$.

Debata, P. K. (2013). The importance of grammar in English language teaching-A reassessment. Language in India, 13(5), 482-486.

Dineen, P. (1989). The Effect of Testing Frequency upon the Achievement of Students in High School Mathematics Courses. School Science and mathematics, 89(3), 197-200.

Doughty, C. J., \& Long, M. H. (2003). Optimal psycholinguistic environments for distance foreign language learning. Language learning \& technology, 7(3), 50-80.

Gholami, V., \& Moghaddam, M. M. (2013). The effect of weekly quizzes on students' final achievement score. International Journal of Modern Education and Computer Science, 5(1), 36.

Haberyan, K. A. (2003). Do weekly quizzes improve student performance on general biology exams? The American Biology Teacher, 65(2), 110-115.

Karpicke, J. D., \& Roediger III, H. L. (2007). Expanding retrieval practice promotes short-term retention, but equally spaced retrieval enhances long-term retention. Journal of experimental psychology: learning, memory, and cognition, 33(4), 704.

Keys, N. (1934). The influence on learning and retention of weekly as opposed to monthly tests. Journal of Educational Psychology, 25(6), 427.

Kling, N., McCorkle, D., Miller, C., \& Reardon, J. (2005). The impact of testing frequency on student performance in a marketing course. Journal of Education for Business, 81(2), 67-72.

Larsen, D. P., \& Butler, A. C. (2009). Test-enhanced learning. Medical Education, 43, 1174-1181.

Lee, B. C., Pandian, A., Rethinasamy, S., \& Tan, D. A. L. (2019). Effects of PWIM in the ESL Classroom: Vocabulary Knowledge Development Among Primary Malaysian Learners. 3L: Language, Linguistics, Literature $\AA, 25(4)$.

Leung, A., \& Kier, C. A. (2017). On Students' Perception of A Multi-Scheme Assessment Method. Journal for 


\section{L: The Southeast Asian Journal of English Language Studies - Vol 26(3): 30 - 40 \\ http://doi.org/10.17576/3L-2020-2603-03}

Economic Educators, 17(1), 40-52.

Loewen, S., Li, S., Fei, F., Thompson, A., Nakatsukasa, K., Ahn, S., \& Chen, X. (2009). Second language learners' beliefs about grammar instruction and error correction. The Modern Language Journal, 93(1), 91-104.

McDaniel, M. A., Wildman, K. M., \& Anderson, J. L. (2012). Using quizzes to enhance summative-assessment performance in a web-based class: An experimental study. Journal of Applied Research in Memory and Cognition, 1(1), 18-26.

Mines Jr, R. O. (2014). The impact of testing frequency and final exams on student performance. In Proceedings of the ASEE Southeastern Section Annual Conference, March.

Nejati, R. (2016). The Durability of the Effect of the Frequent Quizzes on Iranian High School Students' Vocabulary Learning. The International Journal of Humanities, 23(2), 29-42.

Nusrat, A., Ashraf, F., \& Narcy-Combes, M. F. (2019). Effect of Direct and Indirect Teacher Feedback on Accuracy of English Writing: A Quasi-Experimental Study among Pakistani Undergraduate Students. 3L: Language, Linguistics, Literature ${ }^{\circledR}, 25(4)$.

Öncuil, G. (2017). Frequent testing: What are the real impacts of frequent quizzes on students, teachers, and instruction?

Phelps, R. P. (2012). The effect of testing on student achievement, 1910-2010. International Journal of Testing, 12(1), 21-43.

Roediger III, H. L., Agarwal, P. K., McDaniel, M. A., \& McDermott, K. B. (2011). Test-enhanced learning in the classroom: long-term improvements from quizzing. Journal of Experimental Psychology: Applied, 17(4), 382.

Roediger III, H. L., \& Karpicke, J. D. (2006). Test-enhanced learning: Taking memory tests improves long-term retention. Psychological science, 17(3), 249-255.

Schugel, M. (2016). The effects of frequent formative assessment and feedback on summative assessment.

Sheen, Y. (2004). Corrective feedback and learner uptake in communicative classrooms across instructional settings. Language teaching research, 8(3), 263-300

Siddiqui, R., Mannan, N., \& Mannan, F. (2017). student's perception about frequent examinations. Pakistan Journal of Physiology, 13(2), 46-48.

Sun, L. (2017). The Importance of Grammar Teaching at College. In International Conference on Frontiers in Educatioal Technologies and Management Science. Jilin: Jilin Agricultural Science and Technology College.

Thirey, B. (2011). Student Perceptions Regarding the Effectiveness of Daily Quizzes in Collegiate Level Calculus. Center for Teaching Excellence, United States Military, Academy, West Point, NY.

Thomas, R. C., \& McDaniel, M. A. (2013). Testing and feedback effects on front-end control over later retrieval. Journal of Experimental Psychology: Learning, Memory, and Cognition, 39(2), 437.

Trumbo, M. C., Leiting, K. A., McDaniel, M. A., \& Hodge, G. K. (2016). Effects of reinforcement on testenhanced learning in a large, diverse introductory college psychology course. Journal of Experimental Psychology: Applied, 22(2), 148.

Vaessen, B. E., van den Beemt, A., van de Watering, G., van Meeuwen, L. W., Lemmens, L., \& den Brok, P. (2017). Students' perception of frequent assessments and its relation to motivation and grades in a statistics course: a pilot study. Assessment \& Evaluation in Higher Education, 42(6), 872-886.

Wiliam, D. (2011). What is assessment for learning? Studies in educational evaluation, 37(1), 3-14.

Wooldridge, C. L., Bugg, J. M., McDaniel, M. A., \& Liu, Y. (2014). The testing effect with authentic educational materials: A cautionary note. Journal of Applied Research in Memory and Cognition, 3(3), 214-221. 